\title{
Lesson: Design an Efficient Wind Turbine
}

\author{
Olivia Seger ${ }^{1}$ \\ ${ }^{1}$ Affiliation not available
}

April 28, 2021

\section{Overview}

In this lesson, students will design a working wind turbine with a goal of maximizing voltage output. After reviewing types of energy and energy transfer, students will split into groups. They will design and test multiple wind turbine blades using different materials and shapes. After determining the best blade type, students will construct their wind turbines. In the following class period, groups will formally test their turbines to determine which group's turbine produces the highest voltage output. Following the testing, the class will discuss generators and how wind turbines use them to produce electricity. An optional follow-up discussion can then take place about clean energy versus fossil fuels.

\section{Suggested Time: 100 minutes}

\section{Grades: 9-11}

\section{NGSS Standards:}

HS-PS2-5: Plan and conduct an investigation to provide evidence that an electric current can produce a magnetic field and that a changing magnetic field can produce an electric current.

HS-PS3-3: Design, build, and refine a device that works within given constraints to convert one form of energy into another form of energy.

\section{Vocabulary:}

- kinetic energy

- electrical energy

- energy transfer

- wind turbine

- generator

- electromagnetic induction 


\section{Required Materials:}

- DC toy motor (one per group)

- 2 pieces of thin electrical wire with alligator clips (one set per group)

- 1 "x4" piece of wood or stiff ruler (one per group)

- Rubber band (one per group)

- Cork or Styrofoam ball (approximately 1" diameter) (one per group)

- 5 paperclips (one set per group)

- Tape

- Scissors

- Blade materials, such as cardboard, PVC, thin wood, paper, etc (a few pieces of each per group)

- Small fan or hair dryer (1 per class, extras helpful)

- DC voltmeter (1 per class)

\section{Part 1: Energy Transfer Review Lecture (10 minutes)}

1. Review or introduce "kinetic energy", "electrical energy", and "energy transfer".

2. Discuss how energy is conserved but can transfer from one form into another.

3. Analyze the type of energy transfer that take place in a wind turbine.

\section{Part 2: Wind Turbine Blade Testing (40 minutes)}

1. Split students into groups of 3-4.

2. Provide each group with a DC motor mounted onto a piece of wood/ruler with a rubber band attached to a cork or Styrofoam ball.

3. Instruct the groups that they will be designing the blades for the turbine using materials of their choosing.

4. Provide each group with a set of pre-chosen blade materials.

5. Groups will spend the class period designing their blades. Allow students to use the fan/hair dryer as needed to test their blades.

6. Students should use the following guiding questions to design their blades: 1) Which blade material results in the fastest motion without being damaged?, 2) How many blades results in the fastest motion?, 3) Which blade shape results in the fastest motion without being damaged?

\section{Part 3: Wind Turbine Voltage Testing and Discussion (30 minutes)}

1. After designing their blades, students are ready to attach them and test their turbines.

2. Each group will take a turn bringing up their turbines to the DC voltmeter. Use alligator clips to connect the turbine motors to the voltmeters.

3. Use the fan/hair dryer to test the wind turbines. Test each wind turbine from three pre-determined distances. Record the voltage from each distance. 
4. Discuss as a class which blade design was the most efficient. What factors made it the most efficient? Could this design be further improved?

\section{Part 4: Electric Generators and Electromagnetic Induction Discus- sion (20 minutes)}

1. Ask the class to brainstorm what might be inside the DC motor that converts the kinetic energy of the wind turbine blades to electrical energy. Guide students to determine that a magnet is the key components.

2. Introduce the term "electromagnetic induction" and explain the concept to the class.

3. For advanced or honors physics courses, this portion can be expanded to include mathematical components such as Faraday's Law.

4. Diagram the main components of an electric generator and show how it uses electromagnetic induction to convert kinetic energy to electrical energy.

\section{Optional Extension}

This activity can be used to introduce a more broad unit on clean energy versus fossil fuels. Students can research other clean energy devices, such as solar panels or hydroelectric dams. 